\section{Oldest Eurasian stone tools}

\section{Eric Delson}

WHEN and where did the first tool-making humans reside on the European continent? This question was addressed at a recent symposium* in Paris and answered in an article published subsequently by Eugène Bonifay ${ }^{1}$. Bonifay claims that deposits at St Eble, near the extinct Coupet volcano in the Auvergne region of the French Massif Central, yield quartz fragments which testify to the presence of Palaeolithic humans before 2 million years (Myr) ago.

Flaked stone artefacts are the first clear documentation of human cultural behaviour, and thus the earliest stone tools have always been regarded as a watershed in prehistory. In recent decades, the location of these earliest tools has been assumed to be Africa, particularly eastern Africa, given the completeness of tion by Dennell et al. ${ }^{3}$ of several purported stone tools from deposits of that antiquity in Pakistan. In this case there have been questions about the age of the horizon, the primary association of the objects with that horizon and the artefactual nature of the objects, not to mention the lack of human or animal fossils around the objects.

The case for St Eble seems to be stronger. During the meeting, participants from various European countries (from Spain to the Soviet Union) and French regions presented information about the earliest archaeological remains in their territory (see ref. 4 for details). Unfortunately, actual examples of these early artefact assemblages could not be provided, and evaluation of the human origin of such objects, especially when made of quartz or

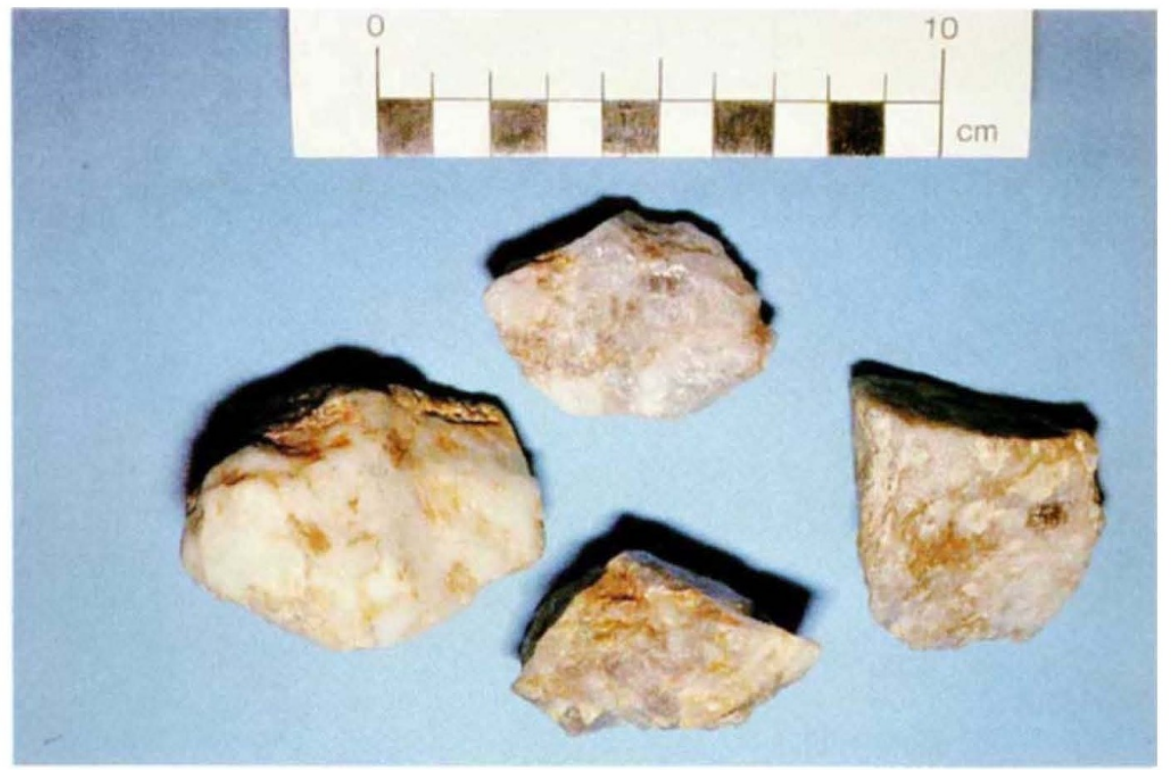

Three purported quartz artefacts from the slope deposits at St Elbe in the Auvergne, and one (in the upper centre) from the fossiliferous silts, dating to greater than 2 Myr age. (Photograph by E. D.)

its fossil record ${ }^{2}$. The acceptance of tools in those sites dated to more than $2 \mathrm{Myr}$ ago is based on the objects being clearly identified as human artefacts, their unquestioned dating by chronometric methods and (in most cases) their association either with human fossils or with animal bones which are apparently linked to human activity.

The suggestion of a similar antiquity for stone tools elsewhere in the world, given the lack of human fossils outside Africa older than about $1.2 \mathrm{Myr}$, immediately elicits reactions ranging from question to disbelief. Such has been the case during the past few years, following the publica-

* The Earliest Human Occupation of Europe, part of the 114th French Nationał Congress of Learned Societies, Paris, 3-9 April 1989. other coarse-grained materials, is difficult when only drawings are available. Many palaeoanthropologists, including myself, have long questioned any reports of artefacts in Europe older than about 0.5 Myr, at which time the earliest human fossils appear there, but several sites discussed at the meeting appear to document human occupation back towards $1 \mathrm{Myr}$ ago at least.

Another group of even less widely accepted sites ranges back to $2.5 \mathrm{Myr}$ ago. Many of these are located in the Massif Central region of France, and an excursion to study them was organized by Bonifay at the end of the meeting. Most of these localities (for example, Soleihac, Ceyssaguet and Chilhac) have been previously reported, and a brief survey has just been published ${ }^{5}$.

But for many the most exciting new locality is St Eble. According to Bonifay ${ }^{1}$, the local stratigraphy comprises a gneiss basement overlain by $3-4 \mathrm{~m}$ of sandy-clay slope deposit and then about $2 \mathrm{~m}$ of bedded volcanic explosion breccias, above which is formed the Coupet volcano itself. On the flank of the volcano is located a younger layer of yellow-orange silt, formed by alteration of the scoria cone and containing a fauna of fossil mammals dating to the middle or late Villafranchian. This local fauna has never been published in detail, nor has the radiometric date of about $2 \mathrm{Myr}$ ago often cited for it - but the latter is in progress by geologists at the University of Clermont-Ferrand. Several artefacts have now been reported from the slope deposit, which could be seen during the excursion to be relatively fine-grained and probably of low-energy origin; Bonifay indicates that no volcanic materials are included within it. If this geological interpretation is correct, the slope deposit is older than 2 Myr and unlikely to yield naturally flaked quartz.

It was not possible to examine the supposed artefacts during the excursion, but I later visited Bonifay's laboratory in Marseilles, where I was shown all available material from this and other localities reported in ref. 5. Several hundred quartz flakes and chunks have been recovered at St Eble, some derived from the basement gneiss and others from heavily rolled pebbles. Bonifay ${ }^{1}$ describes five of these as of unquestioned human manufacture and figured two in line drawings. Three are illustrated in the figure, plus one fragment from the fossiliferous silt. These pieces are not obviously human artefacts, at least to one not expert in dealing with quartz implements, but among specialists there appears to be divided opinion. Further details on the fauna and radioisotope age determination, as well as additional archaeological specimens, will be required before a final decision can be reached on the nature of the St Eble assemblage. But for the time being, it is one of the most intriguing of the purportedly ancient vestiges of human occupation in Europe.

Eric Delson is Professor of Anthropology at Lehman College and the Graduate School, City University of New York and works in the Department of Vertebrate Palaeontology, American Museum of Natural History, New York, New York 10024, USA.

1. Bonifay, E. Comp. Rend. acad. Sci. Paris Ser. II, 308, 1567-1570 (1989)

2. Toth, N. \& Sohick, K. in Advances in Archaeological Method and Theory (ed. Schiffer, M.) 1-96 (Academic, London, 1986).

3. Dennell, R. Curr. Anthrop. 30, 318-322 (1989).

4. Ackerman, S. Science (in the press).

5. Bonifay, E., Consigny, A. \& Liabeuf, L. Comp. Rend. acad. Sci. Paris Ser. II, 308, 1491-1496 (1989). 